\title{
Comparison of Phenotypic and Genotypic Identification Methods of Pasteurella multocida Serotypes Isolated from Pigs
}

\author{
Amanda Figueiredo Amaral', Raquel Rebelatto ${ }^{2}$, Catia Silene Klein², \\ Karine Ludwig Takeuti' \& David Emilio Santos Neves de Barcellos'
}

\begin{abstract}
Background: Pasteurella multocida serotypes A and D are commonly associated with pneumonia and pleuritis in pigs. Different phenotypic techniques, such as hyaluronidase and acriflavine tests, and genotyping techniques, such as PCR, are used to distinguish between these serotypes. The objective of this study was to compare the capsular identification methods of type A and type D P. multocida isolated from pigs using both phenotypic (hyaluronidase and acriflavine tests) and genotypic (multiplex PCR) techniques.

Materials, Methods \& Results: A total of 44 lyophilized P. multocida isolates, obtained between 1981 and 1997 from pig farms at Rio Grande do Sul State, Brazil, were analyzed. The isolates were reactivated in Brain Heart Infusion (BHI) broth and cultured in BHI broth and blood agar supplemented with $5 \%$ sheep blood. Colony identity was further confirmed by evaluating colony morphology in blood agar and confirming the absence of growth on MacConkey agar. Bacteria in Tryptone Soy Agar (TSA) were used for the Triple Sugar Iron (TSI), Sulfide-Indole-Motility (SIM), and nitrate, glucose, lactose, sucrose and mannitol fermentation tests. For hyaluronidase test, $P$. multocida colonies were streaked transversally across the entire plate, approximately 3-5mm apart, in order to observe their lines of growth. Following this, a hyaluronidase producing strain of Staphylococcus aureus was heavily streaked at right angles to the P. multocida lines and the plates were incubated at $37^{\circ} \mathrm{C}$ for $24 \mathrm{~h}$. Type A isolates were then identified as those with smaller colonies in the region adjacent to the Staphylococcus aureus streak (negative satellitism). For acriflavine test, the isolates were inoculated into tubes containing $2 \mathrm{~mL}$ of BHI, incubated at $37^{\circ} \mathrm{C}$ for $18-24 \mathrm{~h}$, centrifuged $(500 \mathrm{~g}$ for $15 \mathrm{~min})$ and $1.5 \mathrm{~mL}$ of the supernatant was discarded. A $1: 1000$ solution of acriflavine neutral $(0.5 \mathrm{~mL})$ was then added to the residual broth containing bacteria and kept at room temperature. Solutions of acriflavine were freshly prepared each week and stored protected from light. Type D strains were identified by the appearance of a heavy flocculent precipitate within $5 \mathrm{~min}$. DNA extraction by heat shock was performed prior to multiplex PCR for the detection of capsular genes hyaD-hyaC (capsular typing A) and $d c b F$ (capsular typing D). Test of symmetry and a weighted kappa coefficient were used to evaluate correlations and to assess agreement of the results between the identification methods, respectively. Phenotypic tests showed that two isolates were type D (4.55\%), 40 were type A (90.9\%) and two (4.55\%) were untypable isolates (4.55\%) while PCR showed that 38 isolates were type A (86.36\%) and six were type $\mathrm{D}(13.64 \%)$. The correlation analysis between the phenotypic and genotypic tests showed that $90.9 \%$ of the strains were identified as belonging to the same serotype by both tests and the weighted kappa coefficient (K $=0.633$ ) indicates a substantial agreement between the two tests.

Discussion: There was a disagreement between the phenotypic and genotypic results in four of the isolates (9.09\%). The phenotypically untypable isolates were classified as type D by multiplex PCR. Nonetheless, we conclude that PCR testing is a more reliable method to differentiate between P. multocida serotypes A and D.
\end{abstract}

Keywords: swine, hyaluronidase, acriflavine, PCR. 


\section{INTRODUCTION}

Pasteurella multocida is a bacteria found worldwide and is associated with pneumonia and pleuritisin pigs [13]. This microorganism is a member of the Pasteurellaceae family considered nutritionally fastidious, growing better in media supplemented with serum or blood, and it does not grow on MacConkey agar [10]. These bacteria can be classify based in its capsule into five serotypes as types A, B, D, E and F [3]. Serotypes A and D are most commonly associated with pneumonia, rhinitis and pleuritis in pigs, but serotype $\mathrm{D}$ is more commonly associated with atrophic rhinitis [13] and serotype A with pneumonia and pleuritis $[2,11,12]$.

A test was developed to identify type A strains after they observed a depolarization of the P. multocida capsule when growning close to a hyaluronidase producing strain of Staphylococcus aureus (negative satellitism) [4]. Another technique was developed to recognize type $\mathrm{D}$ strains based on a floccular reaction of this strain to acriflavine [5]. However, such phenotypic tests have been replaced by PCR-based capsular genotyping techniques [14] which are the current gold standard [6]. Thus, the objective of this study was to compare phenotypic (hyaluronidase and acriflavine tests) and genotypic (multiplex PCR) techniques for the capsular typing of $P$. multocida isolates (type A and type D).

\section{MATERIALS AND METHODS}

Pasteurella multocida isolates

A total of 44 Pasteurella multocida isolates obtained from field cases of pleuritis or pneumonia in pigs in the state of Rio Grande do Sul, Brazil, were used in this study. All samples were isolated between 1981 and 1997 , lyophilized, and stored at $4-8^{\circ} \mathrm{C}$.

The isolates were reactivated in Brain Heart Infusion (BHI) broth ${ }^{1}$, and cultured in BHI broth and a blood agar base ${ }^{1}$ supplemented with 5\% sheep blood. After incubation for 24-48 h, a single colony of $P$. $m u l$ tocida was plated on to blood agar and then on to Tryptone Soy Agar (TSA) and MacConkey agar ${ }^{1}$. Colony identity was further confirmed by evaluating colony morphology in blood agar and confirming the absence of growth on MacConkey agar. Bacteria in TSA were used for the Triple Sugar Iron (TSI), Sulfide-IndoleMotility (SIM), and nitrate, glucose, lactose, sucrose and mannitol ${ }^{2}$ fermentation tests [10]. Subsequently, pure isolates of $P$. multocida were stored in BHI broth containing $50 \%$ sheep blood at $-70^{\circ} \mathrm{C}$.

\section{Phenotype testing}

The isolates were phenotypically classified into two groups, types A or D, based on capsular type, using the hyaluronidase and acriflavine tests.

The hyaluronidase test was performed to classify the isolates in type A [4]. Briefly, P. multocida colonies were streaked transversally across the entire plate, approximately 3-5 mm apart, in order to observe their lines of growth. Following this, a hyaluronidase producing strain of Staphylococcus aureus was heavily streaked at right angles to the P. multocida lines and the plates were incubated at $37^{\circ} \mathrm{C}$ for $18-24 \mathrm{~h}$. Type A isolates were then identified as those with smaller colonies in the region adjacent to the Staphylococcus aureus streak (negative satellitism). The acriflavine test was performed for identifying type D isolates [5]. The isolates were inoculated into tubes containing 2 $\mathrm{mL}$ of BHI, incubated at $37^{\circ} \mathrm{C}$ for $18-24 \mathrm{~h}$, centrifuged (500 $\mathrm{g}$ for $15 \mathrm{~min}$ ) and $1.5 \mathrm{~mL}$ of the supernatant was discarded. A 1:1000 solution of acriflavine neutral (0.5 $\mathrm{mL})^{2}$ was then added to the residual broth containing bacteria and kept at room temperature. Solutions of acriflavine were freshly prepared each week and stored protected from light. Type D strains were identified by the appearance of a heavy flocculent precipitate within $5 \mathrm{~min}$.

\section{Multiplex PCR}

DNA extraction by heat shock was performed prior to multiplex PCR for the detection of capsular genes hyaD-hyaC (capsular typing A) and $d c b F$ (capsular typing D) [14]. The kmtl gene was used for positive identification of the species as it is specific for P. multocida. The sequence of each primer pair and the expected size of each amplicon are described in Table 1.

Briefly, the PCR mix consisted of $2.5 \mu \mathrm{L}$ of 10X PCR buffer; $5 \mu \mathrm{L}$ of $1 \mathrm{mM}$ deoxynucleoside triphosphates; $1 \mu \mathrm{L}$ of CapA primer ${ }^{3}$ pair at 10 pmol; $0.5 \mu \mathrm{L}$ of $\mathrm{CapD}^{3}$ and $k m t 1$ primer $^{4}$ pairs at $10 \mathrm{pmol}$; $0.2 \mu \mathrm{L}$ of Taq DNA polymerase ${ }^{5} ; 1.05 \mu \mathrm{L}$ of $50 \mathrm{mM}$ $\mathrm{MgCl}_{2} ; 4 \mu \mathrm{L}$ of DNA and sterile ultrapure water for a final volume of $25 \mu \mathrm{L}$. Amplification was performed in a thermal cycler ${ }^{6}$ under the following reaction conditions: initial denaturation $\left(95^{\circ} \mathrm{C}\right.$ for $\left.5 \mathrm{~min}\right)$ followed 
by 30 cycles of denaturation $\left(95^{\circ} \mathrm{C}\right.$ for $\left.30 \mathrm{~s}\right)$, annealing $\left(55^{\circ} \mathrm{C}\right.$ for $\left.30 \mathrm{~s}\right)$, elongation $\left(72^{\circ} \mathrm{C}\right.$ for $\left.30 \mathrm{~s}\right)$ and a final elongation stage $\left(72^{\circ} \mathrm{C}\right.$ for $\left.5 \mathrm{~min}\right)$. Electrophoresis of the amplified products was carried out in a $1.5 \%$ agarose gel $^{7}$ stained with ethidium bromide, and the amplified products were visualized in an ultraviolet light transiluminator ${ }^{8}$. P. multocida serotypes A and D were used as a positive control, while sterile ultrapure water was used as a negative control.

\section{Statistical analysis}

Correlations were evaluated using the test of symmetry and a weighted kappa coefficient was used to determine symmetry and assess agreement of the results. For all statistical analysis, a $P$-value $<0.05$ was considered statistically significant (SAS, Version 9.4, 2012).

\section{RESULTS}

The phenotypic tests identified two isolates as type $\mathrm{D}(4.55 \%)$ and 40 isolates as type $\mathrm{A}(90.9 \%)$. Two isolates $(4.55 \%)$ were positive for both the hyaluronidase and acriflavine tests and were, thus, regarded as untypable (Table 2).

Contrarily, the multiplex PCR was able to detect all genes of interest (Table 1) and definitively classify the isolates as either type A or type D. A total of 38 isolates were identified as type A $(86.36 \%)$, while six were identified as type D (13.64\%) [Table 2]. The results of the phenotypic tests did not coincide with those of the multiplex PCR in 4 of the 44 isolates $(9.09 \%)$ tested, and the test of symmetry did not show a significant difference between the identification results from both tests $(P=0.2615)$.

Table 1. Capsule genes selected, primer sequence and amplicon size.

\begin{tabular}{cccc}
\hline Gene & Primer sequence (5'-3') & Primer & Amplicon (pb) \\
\hline \multirow{2}{*}{ hyaD-hyaC } & TGC CAA AAT CGC AGT CAG & CapA F & \multirow{2}{*}{1.044} \\
& TTG CCA TCA TTG TCA GTG & CapA R & \\
\hline \multirow{2}{*}{$d c b \mathrm{~F}$} & TTA CAA AAG AAA GAC TAG GAG CCC & CapD F & \multirow{2}{*}{657} \\
& CAT CTA CCC ACT CAA CCA TAT CAG & CapD R & \\
\hline \multirow{2}{*}{$k m t 1$} & ATC CGC TAT TTA CCC AGT GG & KMT1 T7 & \multirow{2}{*}{460} \\
& GCT GTA AAC GAA CTC GCC AC & KMT1 SP6 & \\
\hline
\end{tabular}

Townsend et al. [14].

Table 2. Correlation of capsular typing results between phenotypic (hyaluronidase and acriflavine) and genotypic (multiplex PCR) tests.

\begin{tabular}{ccccc}
\hline \multirow{2}{*}{ Genotypic } & \multicolumn{3}{c}{ Phenotypic } \\
\cline { 2 - 5 } & A & D & U* & Total \\
\hline A & 38 & 0 & 0 & 38 \\
D & 2 & 2 & 2 & 6 \\
U* & 0 & 0 & 0 & 0 \\
Total & 40 & 2 & 2 & 44 \\
\hline
\end{tabular}

Percentage agreement: 90.9\%. Kappa coefficient: 0.633. (0.404-0.862). *Untypable. 


\section{DISCUSSION}

Phenotypic tests could not conclusively identify 4 of the isolates tested even though the PCR identified them as being type $\mathrm{D}$, and others have reported similar results. Another study has reported that 55 of 114 (48.24\%) P. multocida strains obtained from different animal hosts, including pigs, were untypable using only the hyaluronidase and acriflavine tests [1]. However, in that study, unlike our study, the strains classified as untypable were negative for both the hyaluronidase and acriflavine tests. Similarly, it was found that 11 of $54(20.37 \%)$ strains isolated during a fowl cholera outbreak in Brazil were untypable using these phenotypic tests [7].

The phenotypically untypable isolates were classified as type D by multiplex PCR. This can be explained by the fact that some type D strains show a slight reduction in colony size when grown near a Staphylococcus aureus streak, which indicates that these strains may possess a small amount of peripheral hyaluronic acid [4]. Phenotypic tests results can also change in some $P$. multocida isolates when they produce capsules with different properties as part of the colony ageing process or even as a response to changes in the composition of the medium [8].

A correlation analysis between the phenotypic and genotypic tests showed that $90.9 \%$ of the strains were identified as belonging to the same serotype by both tests (Table 2), and the weighted kappa coefficient
$(\mathrm{K}=0.633)$ indicates a substantial agreement between the two tests [9]. Nonetheless, since the multiplex PCR is based on the presence of the capsule gene and not the capsule itself, the PCR was able to definitively identify the isolates.

\section{CONCLUSION}

The results of this study showed that little discrepancies between phenotypic and genotypic testing methods can occur. It was concluded that the PCR method is more efficient compared to the phenotypic methods for clearly distinguishing between P. multocida serotypes A and D.

\section{MANUFACTURERS \\ ${ }^{1} \mathrm{Oxoid}^{\circledR}$. Cambridge, UK. \\ ${ }^{2}$ Sigma ${ }^{\circledR}$. Saint Louis, MO, USA. \\ ${ }^{3}$ IDT. San Diego, CA, USA. \\ ${ }^{4}$ Bioneer. Alameda, CA, USA. \\ ${ }^{5}$ Invitrogen. Carlsbad, CA, USA. \\ ${ }^{6}$ Eppendorf. Hamburg, Germany. \\ ${ }^{7}$ Easy Path. São Paulo, SP, Brazil. \\ ${ }^{8}$ Loccus Biotecnologia. Cotia, SP, Brazil.}

Acknowledgments. The authors thank Capes for financial support and Dr. Arlei Coldebella (Embrapa Suínos e Aves Concórdia, SC, Brazil) for help in statistical analysis.

Declaration of interest. The authors report no conflicts of interest. The authors alone are responsible for the content and writing of the paper.

\section{REFERENCES}

1 Arumugam N.D., Ajam N., Blackall P.J., Asiah N.M., Maria J., Yuslan S. \& Thong K.L. 2011. Capsular serotyping of Pasteurella multocida from various animal hosts - a comparison of phenotypic and genotypic methods. Tropical Biomedicine. 28(1): 55-63.

2 Borowski S.M. 2001. Caracterização e estudo de virulência de amostras de Pasteurella multocida isoladas de suínos no estado do RS, Brasil. 163p. Porto Alegre, RS. Dissertation (PhD in Veterinary Science) - Programa de Pós-graduação em Ciências Veterinárias, Universidade Federal do Rio Grande do Sul.

3 Carter G.R. 1955. Studies on Pasteurella multocida I. A haemoagglutination test for the identification of serological types. American Journal of Veterinary Research. 16: 481-484.

4 Carter G.R \& Rundell D.W. 1975. Identification of type A strains of Pasteurella multocida using staphylococcal hyaluronidase. The Veterinary Record. 87: 343.

5 Carter G.R. \& Subronto P. 1973. Identification of type D strains of Pasteurella multocida with acriflavine. American Journal of Veterinary Research. 34(2): 293-294.

6 Dziva F., Muhairwa A.P., Bisgaard M. \& Christensen H. 2008. Diagnostic and typing options for investigation diseases associated Pasteurella multocida. Veterinary Microbiology. 128: 1-22.

7 Furian T.Q., Borges K.A., Pilatti R.M., Almeida C., do Nascimento V.P., Salle C.T.P. \& de S. Moraes H.L. 2014. Identification of the capsule type of Pasteurella multocida isolates from cases of fowl cholera by multiplex PCR and comparison with phenotypic methods. Brazilian Journal of Poultry Science. 16(2): 31-36. 
8 Glisson J.R. 2008. Pasteurellosis and other respiratory bacterial infection. In: Saif Y.M., Fadly A.M., Glisson J.R., McDougald L.R., Nolan L.K. \& Swayne D.E. (Eds). Diseases of Poultry.12th edn. Ames: Blackwell Publishing, pp.739758.

9 Landis J.R. \& Koch G.G. 1977. The measurement of observer agreement for categorical data. Biometrics. 33: 159174.

10 Markey B., Leonard F., Archambault M., Culliname A. \& Maguire D. 2013. Pasteurella, Mannheimia, Bibersteinia and Avibacterium species. In: Markey B., Leonard F., Archambault M., Cullinane A. \& Maguire D. (Eds). Clinical Veterinary Microbiology. 2nd edn. Toronto: Elsevier, pp.307-316.

11 Mores M.A.S. 2006. Anatomopatologia e bacteriologia de lesões pulmonares responsáveis por condenações de carcaças em suínos. 91p. Curitiba, PR. Thesis. (M.Sc. in Veterinary Medicine) - Programa de Pós-graduação em Ciências Veterinárias, Universidade Federal do Paraná.

12 Pijoan C. 2006. Pneumonic Pasteurellosis. In: Straw B.E., Zimmerman J.J., D’Allaire S. \& Taylor D.J. (Eds). Disease of Swine. 9th edn. Ames: State University Press, pp.719-726.

13 Register K.B., Brockmeier S.L., De Jong M.F. \& Pijoan C. 2012. Pasteurellosis. In: Zimmerman J.J., Karriker L.A., Ramirez A., Schwartz K.J. \& Stevenson G.W. (Eds). Diseases of Swine.10th edn. Ames: Wiley-Blackwell, pp.798-810.

14 Townsend K.M., Boyce J.D., Chung J.Y., Frost A.J. \& Adler B. 2001. Genetic organization of Pasteurella multocida cap Loci and development of a multiplex capsular PCR typing system. Journal of Clinical Microbiology. 39(3): 924929. 